\title{
Severe refractory asthma: an update
}

\author{
Reinier R.L. Wener and Elisabeth H. Bel
}

Affiliations: Dept of Respiratory Medicine, Academic Medical Centre, Amsterdam, The Netherlands.

Correspondence: R.R.L. Wener, Dept of Respiratory Medicine, Academic Medical Center, P.0. Box 22660, 1100 DE Amsterdam, the Netherlands. E-mail: r.r.wenerdamc.uva.nl

ABSTRACT Asthma is a heterogeneous disease in which adequate asthma control cannot be achieved in a substantial proportion despite currently available treatment possibilities. This subgroup has been defined as "severe refractory" asthma. Over the past years considerable progress has been made regarding a more exact definition of severe refractory asthma. A systematic approach to evaluate the asthma patient has been postulated. Further detailed classification into distinct phenotypes is ongoing to target the right treatment to the right patient. And, new therapeutic targeted treatment options are currently in development to provide possible new targets to improve disease state, symptoms and quality of life. This review will provide an update on the latest advancements with regard to all these domains.

0

@ERSpublications

Phenotyping the severe asthma patient is essential to ensure the right treatment is given to the right patient http://ow.ly/mOQrQ

\section{Introduction}

The majority of patients with asthma can be treated effectively with the currently available medications. However, a significant proportion of patients labelled as "severe refractory asthma" remain a challenge for the treating clinician. Severe refractory asthma encompasses a variety of subphenotypes of asthma that do not respond to current standard therapy, i.e. high doses of inhaled glucocorticosteroids in combination with long-acting $\beta_{2}$-agonists (LABA) $[1,2]$. Management of severe asthma is associated with a high and disproportional consumption of healthcare resources $[3,4]$. In addition, there exists a substantial unmet clinical need. Therefore, much research is currently ongoing on topics such as assessment and evaluation, subphenotyping and novel treatment modalities for severe asthma. This review will focus on the most recent research developments regarding severe refractory asthma.

\section{Defining severe refractory asthma}

Over the past decade, much effort has been directed towards defining severe refractory asthma. The most important progress encompassed the distinction between uncontrolled asthma, difficult-to-control asthma and severe refractory asthma [5-7].

It started in 1999 when a European Respiratory Society (ERS) Task Force defined difficult asthma as "asthma remaining uncontrolled despite high dose inhaled glucocorticosteroids with or without systemic glucocorticosteroids", and uncontrolled asthma as "persistent asthma symptoms or recurrent exacerbations" (table 1) [2]. A year later, the American Thoracic Society (ATS) definition of severe refractory asthma was very similar, and included six criteria that specified asthma control [1]. In 2010, the World Health Organization (WHO) added responsiveness to treatment to the definition, as well as future risk as an indicator for asthma control [8]. The WHO distinguished three subtypes of severe asthma: 1) severe untreated asthma, 2) difficult-to-control severe asthma, and 3) severe refractory asthma. In 2011, the Innovative Medicines Initiative introduced the term "problematic" asthma to cover all patients with

Received: March 302013 | Accepted after revision: April 252013

Conflict of interest: Disclosures can be found alongside the online version of this article at err.ersjournals.com

Provenance: Publication of this peer-reviewed article was supported by the World Scleroderma Foundation, Switzerland (principal sponsor, European Respiratory Review issue 129).

Copyright @ERS 2013 
TABLE 1 Evolution of the definition of "severe" asthma

ERS, 1999

ATS, 2000

WHO, 2010

IMI, 2011

ATS/ERS, 2013
Difficult asthma

Uncontrolled asthma

Severe refractory asthma

Poorly controlled asthma
Asthma remaining uncontrolled despite high-dose inhaled glucocorticosteroids with or without systemic glucocorticosteroids Persistent asthma symptoms or recurrent exacerbations According to an ERS Task Force including criteria that specifies asthma control

Addition of responsiveness to treatment and future risk as a marker for asthma control

Algorithm to distinguish difficult-to-control asthma from severe refractory asthma

Latest recommendations on the identification, evaluation and treatment of patients with severe refractory asthma

ERS: European Respiratory Society; ATS: American Thoracic Society; WHO: World Health Organization; IMI: Innovative Medicines Initiative.

"poorly controlled" asthma [7] and published an algorithm on how to distinguish difficult-to-control asthma from severe refractory asthma. This algorithm addressed all factors that can make asthma difficult to control, including non-adherence to treatment, inadequate inhalation technique, continuous exposure to environmental triggers and comorbidities. A joint Task Force of the ERS and the ATS will publish the latest recommendations on the identification, evaluation and treatment of patients with severe refractory asthma in the near future.

\section{Aggravating factors and comorbidities}

Distinguishing severe refractory asthma from difficult-to-control asthma is critically important because it identifies the patients who may benefit from novel and, sometimes, expensive treatments. A high percentage of patients who are labelled with severe or difficult-to-control asthma actually do not have severe refractory asthma. Early studies already emphasised that comorbid conditions or inadequate treatments may interfere with asthma control and severity of symptoms [9]. Cleary, a systematic evaluation is of great value, as has been shown by several research groups $[10,11]$. Such an approach can reveal an incorrect diagnosis and comorbid conditions that aggravate asthma, such as gastro-oesophageal reflux, obstructive sleep apnoea, sinonasal disease, recurrent respiratory infections and obesity. Also, non-adherence with inhaled glucocorticosteroid treatment and incorrect inhalation technique are frequently encountered factors that perpetuate poorly controlled asthma [12-16]. Addressing and treating these factors has been shown to result in better clinical outcomes [10,11]. A systematic evaluation of patients with difficult-to-control asthma should include the confirmation of the diagnosis of asthma, assessment of disease severity, evaluation of risk factors, comorbid conditions and other factors that prohibit asthma control [17]. A standard protocol for evaluating difficult-to-control asthma has never been agreed upon but a comprehensive overview of investigations that these patients could or should undergo has recently been published [17]. In that review, the authors emphasise to perform such investigations in a dedicated multidisciplinary centre with special interest and experience in managing these patients [17].

\section{Subphenotypes of severe refractory asthma}

Severe refractory asthma is a heterogeneous condition, and over the past few years several clinical phenotypes have been identified by the use of supervised and unsupervised cluster analysis [18-21]. These phenotypes are characterised by different clinical and physiological features, probably reflecting separate immuno-pathologies [22]. Thus, characterisation of sub-phenotypes of severe asthma may be very helpful in understanding the underlying pathophysiology and may be used to target treatment.

In the Severe Asthma Research Program (SARP) five subphenotypes were identified by unsupervised cluster analysis of which three were severe asthma [19]. One cluster of severe asthma constituted mainly of patients with early onset severe allergic asthma with very low forced expiratory volume in $1 \mathrm{~s}$ (FEV1), a second cluster of patients mainly had late onset non-atopic, steroid dependent asthma with fixed airways obstruction and a third cluster was characterised by mainly older, obese females with late onset asthma and reduced lung function [19]. In another landmark study that used cluster analysis to identify asthma phenotypes, sputum eosinophilia was also incorporated. This led to slightly different clustering of patients with severe asthma, including a cluster of early onset severe atopic asthma, a cluster of predominantly male patients with late onset asthma with severe persistent eosinophilic airway inflammation, and a cluster of obese females with late onset asthma without eosinophilia (table 2) [18]. 


\section{TABLE 2 Identified phenotypes of severe refractory asthma}

Early onset severe allergic asthma

Late onset non-atopic, inflammation predominant asthma with fixed airflow limitation

Late onset obese female preponderant asthma

Currently, a pan-European project (U-BIOPRED) is being conducted to further fingerprint the distinct phenotypes of severe asthma by integrating high dimensional data from invasive (bronchial biopsies), noninvasive (blood, sputum and exhaled air) and patient-reported outcomes, and using an innovative systems biology approach [7].

\section{Current treatment of severe asthma}

According to current guidelines (Global Initiative for Asthma, National Asthma Education and Prevention Programme and the British Thoracic Society) the treatment of patients with severe asthma constitutes of high-dose inhaled or oral glucocorticosteroids in combination with LABAs and/or additional controller medications [1].

\section{Inhaled glucocorticosteroids}

High-dose inhaled glucocorticosteroids, sometimes even in higher dosages than maximally recommended, are used to treat patients with severe asthma. There is, however, no evidence that these ultra-high doses lead to better control of asthma, improve lung function or ameliorate asthma-related quality of life [23, 24]. Care givers need to realise that such high doses of inhaled steroids may be associated with systemic sideeffects in the long run including adrenal suppression, skin thinning, ecchymoses, reduced bone mineral density, glaucoma and cataract $[25,26]$. Therefore, dosages higher than recommended should not routinely be prescribed to patients with severe asthma. In many cases, however, systemic anti-inflammatory treatment with low doses of systemic glucocorticosteroids is required to maintain some degree of asthma control.

\section{$\beta_{2}$-agonists}

There is no doubt that both short-acting $\beta_{2}$-agonists (SABAs) and LABAs improve asthma control and reduce asthma exacerbations $[27,28]$. However, (unintended) overuse of SABAs may paradoxically lead to unfavourable asthma outcomes [29], with loss of effectiveness and increased airway hyperresponsiveness [30]. Furthermore, sudden cessation of regular $\beta_{2}$-agonists may lead to rebound bronchoconstriction as a result of pharmacological dependence [31,32]. Fortunately, careful tapering of $\beta_{2}$-agonist overuse can result in improved asthma control [33]. Therefore, SABAs should be prescribed only as needed.

Also the use of LABAs has been associated with unfavourable adverse effects, including an increased risk of serious exacerbations and asthma-related deaths, in particular if not combined with inhaled glucocorticosteroids [34, 35]. Although inhaled glucocorticosteroids are often prescribed in a (fixed) combination with a LABA, careful instruction and monitoring are needed to prevent potential negative side-effects in selected patients [36]. Several once daily $\beta_{2}$-agonists (ultra-LABAs) such as indacaterol, carmoterol, olodaterol, vilanterol and LAS100977 are currently under investigation [37]. Because of the earlier described side-effects, once daily $\beta_{2}$-agonists should also be prescribed in fixed dose combinations. Results of these trials will be available in the near future.

\section{Anti-cholinergic agents}

Anti-cholinergic agents can be used as an alternative for $\beta_{2}$-agonists in the treatment of patients with severe asthma. The long-acting anti-cholinergic agent tiotropium has been shown to be beneficial in patients with moderate-to-severe uncontrolled asthma with improvement of symptoms, pulmonary function [38, 39], and time to first exacerbation [40]. However, increased mortality rates from cardiovascular causes have been reported in patients with chronic obstructive pulmonary disease who used tiotropium via a mist inhaler. Therefore, caution should be exercised in prescribing long-acting anti-cholinergic agents to patients with severe asthma and an increased cardiovascular risk [41].

\section{New classes of bronchodilator therapy}

Because the long-term safety of $\beta_{2}$-agonist therapy in asthma has been a controversial and unresolved issue for more than two decades [34, 35, 42, 43], alternative classes of bronchodilator therapy have been developed. Vasoactive intestinal peptide analogues and potassium channel openers, i.e. agonists of bitter taste receptors (TAS2Rs), have shown bronchodilator effects [44-46]. Unfortunately, these drugs have had more potent vasodilator than bronchodilator effects. In addition, it remains unclear which mechanism 
provides bronchodilation in these potassium channel openers [47]. Furthermore, combined phosphodiesterase 3/4 inhibitors are currently under development as bronchodilator therapy [48]. However, in the near future it is not to be expected that these drugs will be available for patients with severe persistent asthma.

\section{Phenotype-specific treatment}

It is increasingly recognised that different asthma phenotypes respond differently to asthma treatments. Phenotyping the severe asthma patient is therefore essential to ensure the right treatment is given to the right patient.

\section{Early onset severe allergic asthma}

Allergic, T-helper type-2 driven asthma is the most common and best understood subphenotype of severe refractory asthma. In this phenotype, IgE plays an important role $[49,50]$. Airways from patients who died during a severe asthma attack have shown a high expression of the high-affinity IgE surface receptor on mast cells and basophils, indicating that these patients were at high risk of IgE mediated reactions and exacerbations [51]. Anti-IgE therapy has been designed as a targeted therapy for this asthma subphenotype, although predicting the response to this therapy on the basis of elevated plasma IgE levels has been disappointing [52]. Studies have shown that the anti-IgE agent omalizumab is a safe and effective treatment in severe allergic asthma. It reduces the exacerbation rate and improves asthma control allowing a reduction of inhaled glucocorticosteroid dosage and use of rescue medication [53-56].

\section{Late onset non-atopic, inflammation predominant asthma with fixed airflow limitation}

This severe refractory asthma phenotype is characterised by later onset in life (after the age of 12 years), more severe (eosinophilic) airway inflammation and more frequent association with rhino sinusitis and nasal polyposis. There is also an association with aspirin sensitivity [57], small airways inflammation $[57,58]$ and persistent eosinophilia [59]. Chronic rhino-sinusitis and nasal polyps, as well as persistent airway eosinophilia, are risk factors for uncontrolled asthma and asthma exacerbations [14, 60]. Clinicians should be aware that many patients with severe asthma have an asymptomatic chronic rhino-sinusitis on detailed examination [61]. Since treatment of chronic rhino-sinusitis has been shown to lead to improved asthma control and an increase in pulmonary function [62], the presence of this comorbid condition should be routinely checked and treated if necessary.

Persistent eosinophilia is the most important characteristic of this subphenotype of severe refractory asthma [59]. It correlates with disease severity and is associated with fixed airflow limitation [60], frequent asthma exacerbations and hospitalisations [63], and a higher frequency of intubations [64]. Because of the proposed association of persistent eosinophilia with small airway inflammation [58] there might be a role for ultrafine inhaled glucocorticosteroids in these patients. These drugs have been shown to reduce the number of eosinophils in small airway biopsies and to decrease the rate of asthma exacerbations [65, 66]. Still, many patients with the persistent eosinophilic phenotype need low dose systemic glucocorticosteroids to maintain acceptable asthma control [67, 68]. Unfortunately, chronic systemic glucocorticosteroid use has serious dose- and time-dependent side-effects, such as osteoporosis, diabetes, hypertension, cataract formation and myopathy $[69,70]$. Therefore, tapering oral glucocorticosteroids to the lowest effective dose is of high priority [69]. Classical steroid sparing treatments including oral gold [71], methotrexate [72] and ciclosporin [73] have not gained acceptance because of limited effects and significant side-effects.

Because of its important role in propagating airway inflammation, targeting the eosinophil itself has been shown to be an effective treatment strategy for patients with severe eosinophilic asthma. Studies with the anti-interleukin (IL)-5 agent mepolizumab showed a significant reduction of the rate of asthma exacerbations in patients who had eosinophils in sputum despite high-dose inhaled or oral glucocorticosteroids. The treatment appeared to be safe and well tolerated. Mepolizumab treatment was also associated with improved symptom control and quality of life in these patients [74-76]. In addition, a small study in oral steroid-dependent asthma showed that mepolizumab was also effective in preventing exacerbations when tapering the oral glucocorticosteroid dose [74]. Large scale studies are now ongoing to confirm that this treatment can be used as a steroid-sparing agent or even as an alternative for oral glucocorticosteroids.

\section{Late onset obese female preponderant asthma}

This phenotype has increasingly been recognised over the past years, probably due to the rapidly increasing prevalence of morbid obesity $[15,77]$. The association between obesity and severe asthma is complex and poorly understood. Proposed mechanisms include expiratory flow limitation secondary to mechanical factors [78], pro-inflammatory effects of adipose tissue on the airways [79], and a high prevalence of 
comorbidities that may aggravate existing asthma, in particular sleep-disordered breathing and gastrooesophageal reflux disease [80].

Obesity is associated with loss of asthma control, poor quality of life, more asthma-related unscheduled visits and hospitalisations, and blunted response to glucocorticosteroid treatment [81]. Weight reduction is the only effective treatment for these patients. It has been shown that drastic weight reduction improves pulmonary function, airway hyperresponsiveness, asthma control and asthma-related quality of life [82]. Similar results can be obtained with bariatric surgery [77].

Sleep-disordered breathing, which is a major problem in obese patients, is more prevalent in severe asthma [83], and is also associated with poorly controlled asthma [84]. Therapy with continuous positive airway pressure has been shown to improve asthma control and quality of life [85, 86], although no change in pulmonary function or airway hyperresponsiveness has been observed [86]. Therefore, sleep-disordered symptoms should be routinely assessed and polysomnography should be performed if necessary.

Gastro-oesophageal reflux disease is also highly prevalent in severe asthma [87]. However, the majority of patients are asymptomatic, and in patients with uncontrolled moderate-to-severe asthma treatment with proton-pump inhibitors has not been shown to improve asthma control [87]. Therefore, such treatment is only recommended in patient suffering from symptoms of gastro-oesophageal reflux.

\section{Other targeted treatments}

Several biological pathways have been shown to play a role in asthma pathogenesis, and these pathways do not always overlap with the clinical phenotypes described above. Therefore, phenotyping at multiple levels is important to acquire the responder to targeted therapy. Several targets for treatment have been identified and multiple drugs are now under investigation (table 3).

Whereas anti-IL-5 therapy (mepolizumab and reslizumab) has been shown to be effective in reducing exacerbation rates in eosinophilic asthma $[74-76,88]$, no effect was observed on lung function or airway hyperresponsiveness. Other targeted treatments, such as tumour necrosis factor (TNF)- $\alpha$ blocking agents (golimumab [89] and etanercept $[90,91]$ ) have shown beneficial effects on exacerbation rate, but not on lung function in the subgroups of adults with severe asthma with $\geqslant 12 \%$ reversibility in baseline FEV1. This dissociation between asthma exacerbations and lung function is intriguing, and suggests that different mechanisms determine airway patency at rest and the occurrence of asthma exacerbations. TNF- $\alpha$ blockers have not been further developed for the treatment of severe asthma patients because of several serious adverse events, including pulmonary infections and malignancies [89]. Other novel experimental therapies include daclizumab, a humanised IgG1 monoclonal antibody against the IL-2R chain of activated lymphocytes. This agent showed improvement in asthma scores and pulmonary function [92]. Furthermore, a CXCR2 antagonist showed modest improvement in exacerbation rate without improvement in asthma control in a subgroup of asthma patients with increased sputum neutrophils [93]. Antibodies against IL-13, lebrikizumab, showed improved pulmonary function testing but no effect on exacerbation rate or symptoms [94]. Another anti-IL-13 antibody, tralokinumab, showed improved pulmonary function without improvement of asthma symptom scores, although patients seemed to need less rescue medication [95]. In an unselected group of moderate-to-severe asthma patients the use of AMG 317, an anti-IL4 receptor blocker, showed no clinical benefit at all [96]. All these monoclonal antibodies had an acceptable safety profile.

Most of these studies have been performed without appropriate phenotyping of the patients, which could have led to false-negative results. Further studies are required to detect the right patients for the target concerned.

\section{Nonpharmacological "targeted" treatment \\ Bronchial thermoplasty}

Preliminary investigations with radiofrequency ablation of airway smooth muscle have offered a novel promising treatment option in severe refractory asthma [97]. Several studies showed improved pulmonary function testing, airway hyperresponsiveness, asthma-related quality of life and symptom scores [98, 99]. Other studies did not confirm these results but showed a decrease in the rate of asthma exacerbations and hospitalisations [100]. No clinical complications were observed in the long run, and pulmonary function remained stable over a period of 5 years [101]. Therefore, this approach might be a reasonable option for patients not responding to current treatment. However, it is still not clear which clinical outcome responds best to this treatment and which subgroups of patients with severe asthma benefit the most.

\section{High altitude treatment}

Most patients with severe asthma benefit from a stay at high altitude [102, 103]. The high altitude climate offers decreased levels of house dust mite allergens and decreased exposure to pollens, fungal spores and air 
TABLE 3 Targeted treatment in severe refractory asthma

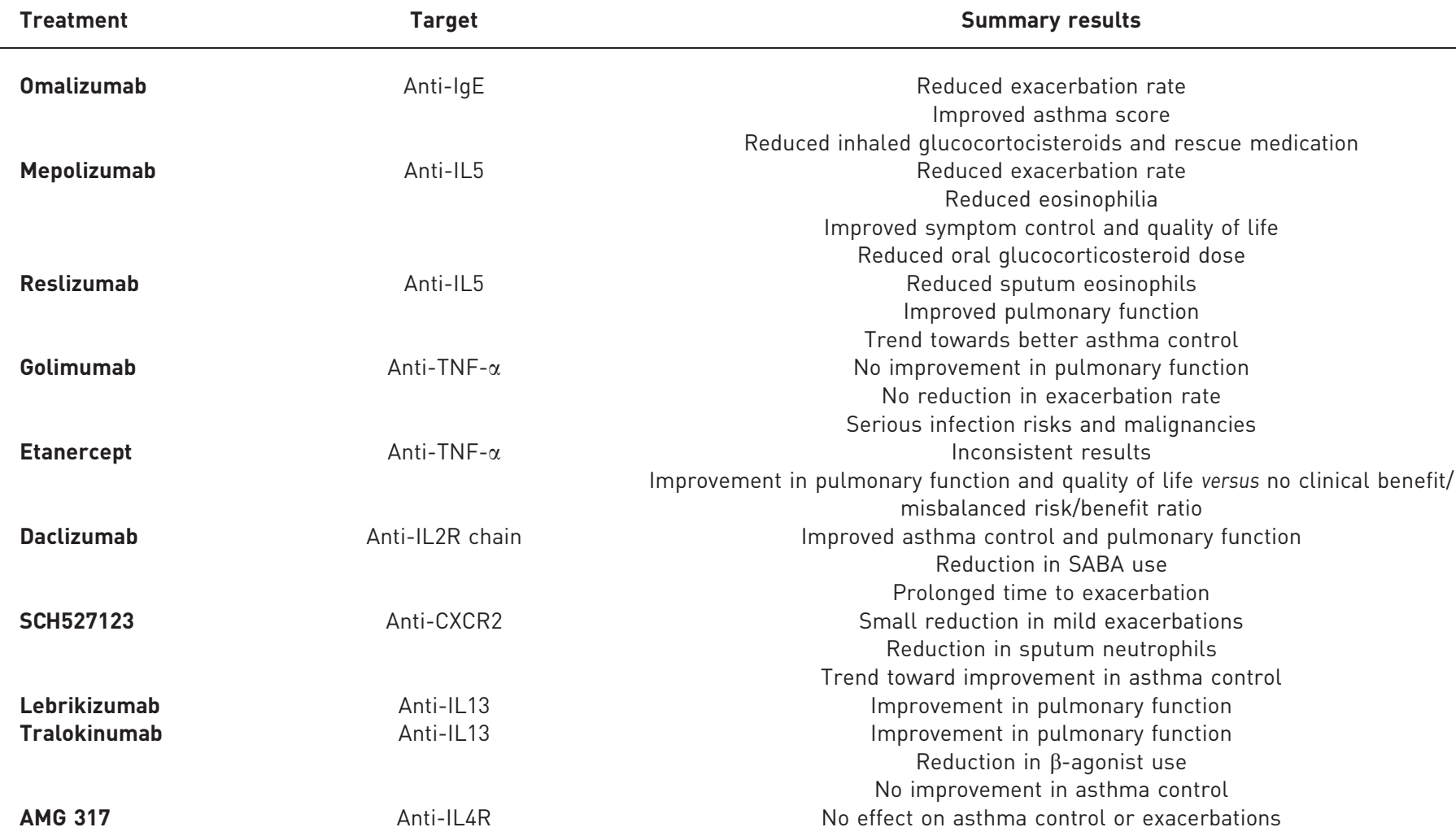

IL: interleukin; TNF; tumour necrosis factor; IL2R: interleukin-2 receptor; SABA: short-acting $\beta$-agonist.

pollution. At high altitude patients may benefit from lower work of breathing due to reduced gas density, relief from stress and high exposure to UV light, which has a potential immunomodulatory effect [102]. A periodic rehabilitation programme at high altitude might be a good treatment option for patients with severe refractory asthma, irrespective of the asthma phenotype, who remain uncontrolled at sea level despite maximally recommended doses of asthma medications.

\section{Future perspectives and conclusion}

Severe asthma is a heterogeneous and complex disease requiring a multidisciplinary approach. Identifying the true "severe refractory asthma" patient is the first step in management. The second step is to phenotype the patient as accurately as possible. Until now, only clinical phenotyping has been used in clinical practice to guide treatment. Unbiased cluster analysis has already revealed three to four subphenotypes of severe asthma $[18,19]$. In the near future, integrated high dimensional data will probably lead to more accurate phenotyping [104]. This will certainly improve our understanding of the patho-immunobiology of the different asthma phenoypes and will help clinicians to better predict the natural history and prognosis of an individual patient with asthma. However, the most important outcome of this systems medicine approach will be the development of new and better treatment targets/strategies for this complex group of patients with severe refractory asthma.

\section{References}

1 Proceedings of the ATS workshop on refractory asthma: current understanding, recommendations, and unanswered questions. American Thoracic Society. Am J Respir Crit Care Med 2000; 162: 2341-2351.

2 Chung KF, Godard P, Adelroth E, et al. Difficult/therapy-resistant asthma: the need for an integrated approach to define clinical phenotypes, evaluate risk factors, understand pathophysiology and find novel therapies. ERS Task Force on Difficult/Therapy-Resistant Asthma. Eur Respir J 1999; 13: 1198-1208.

3 Godard P, Chanez P, Siraudin L, et al. Costs of asthma are correlated with severity: a 1-year prospective study. Eur Respir J 2002; 19: 61-67.

4 Ivanova JI, Bergman R, Birnbaum HG, et al. Effect of asthma exacerbations on health care costs among asthmatic patients with moderate and severe persistent asthma. J Allergy Clin Immunol 2012; 129: 1229-1235. 
5 Reddel HK, Taylor DR, Bateman ED, et al. An official American Thoracic Society/European Respiratory Society statement: asthma control and exacerbations: standardizing endpoints for clinical asthma trials and clinical practice. Am J Respir Crit Care Med 2009; 180: 59-99.

6 Global strategy for asthma management and prevention. Global Initiative for Asthma (GINA) 2006. Available from www.ginasathma.org

7 Bel EH, Sousa A, Fleming L, et al. Diagnosis and definition of severe refractory asthma: an international consensus statement from the Innovative Medicine Initiative (IMI). Thorax 2011; 66: 910-917.

8 Bousquet J, Mantzouranis E, Cruz AA, et al. Uniform definition of asthma severity, control, and exacerbations: document presented for the World Health Organization Consultation on Severe Asthma. J Allergy Clin Immunol 2010; 126: 926-938.

9 Irwin RS, Curley FJ, French CL. Difficult-to-control asthma. Contributing factors and outcome of a systematic management protocol. Chest 1993; 103: 1662-1669.

10 Robinson DS, Campbell DA, Durham SR, et al. Systematic assessment of difficult-to-treat asthma. Eur Respir J 2003; 22: 478-483.

11 Heaney LG, Conway E, Kelly C, et al. Predictors of therapy resistant asthma: outcome of a systematic evaluation protocol. Thorax 2003; 58: 561-566.

12 Murphy AC, Proeschal A, Brightling CE, et al. The relationship between clinical outcomes and medication adherence in difficult-to-control asthma. Thorax 2012; 67: 751-753.

13 Moore WC, Bleecker ER, Curran-Everett D, et al. Characterization of the severe asthma phenotype by the National Heart, Lung, and Blood Institute's Severe Asthma Research Program. J Allergy Clin Immunol 2007; 119: 405-413.

14 ten Brinke A, Sterk PJ, Masclee AA, et al. Risk factors of frequent exacerbations in difficult-to-treat asthma. Eur Respir J 2005; 26: 812-818.

15 Holguin F, Bleecker ER, Busse WW, et al. Obesity and asthma: an association modified by age of asthma onset. J Allergy Clin Immunol 2011; 127: 1486-1493.

16 Boulet LP, Boulay ME. Asthma-related comorbidities. Expert Rev Respir Med 2011; 5: 377-393.

17 Gibeon D, Chung KF. The investigation of severe asthma to define phenotypes. Clin Exp Allergy 2012; 42: 678-692.

18 Haldar P, Pavord ID, Shaw DE, et al. Cluster analysis and clinical asthma phenotypes. Am J Respir Crit Care Med 2008; 178: 218-224.

19 Moore WC, Meyers DA, Wenzel SE, et al. Identification of asthma phenotypes using cluster analysis in the Severe Asthma Research Program. Am J Respir Crit Care Med 2010; 181: 315-323.

20 Siroux V, Basagana X, Boudier A, et al. Identifying adult asthma phenotypes using a clustering approach. Eur Respir J 2011; 38: 310-317.

21 Sutherland ER, Goleva E, King TS, et al. Cluster analysis of obesity and asthma phenotypes. PLoS One 2012; 7: e36631.

22 Wenzel SE. Asthma phenotypes: the evolution from clinical to molecular approaches. Nat Med 2012; 18: 716-725.

23 Adams NP, Bestall JC, Jones P, et al. Fluticasone at different doses for chronic asthma in adults and children. Cochrane Database Syst Rev 2008; 4: CD003534.

24 Reddel HK, Jenkins CR, Marks GB, et al. Optimal asthma control, starting with high doses of inhaled budesonide. Eur Respir J 2000; 16: 226-235.

25 Baptist AP, Reddy RC. Inhaled corticosteroids for asthma: are they all the same? J Clin Pharm Ther 2009; 34: 1-12.

26 Mortimer KJ, Tata LJ, Smith CJ, et al. Oral and inhaled corticosteroids and adrenal insufficiency: a case-control study. Thorax 2006; 61: 405-408.

27 Pauwels RA, Lofdahl CG, Postma DS, et al. Effect of inhaled formoterol and budesonide on exacerbations of asthma. Formoterol and Corticosteroids Establishing Therapy (FACET) International Study Group. N Engl J Med 1997; 337: 1405-1411.

28 Bateman ED, Boushey HA, Bousquet J, et al. Can guideline-defined asthma control be achieved? The Gaining Optimal Asthma ControL study. Am J Respir Crit Care Med 2004; 170: 836-844.

29 Hall IP. The $\beta$-agonist controversy revisited. Lancet 2004; 363: 183-184.

30 Wahedna I, Wong CS, Wisniewski AF, et al. Asthma control during and after cessation of regular $\beta 2$-agonist treatment. Am Rev Respir Dis 1993; 148: 707-712.

31 Broadley KJ. $\beta$-adrenoceptor responses of the airways: for better or worse? Eur J Pharmacol 2006; 533: 15-27.

32 Sears MR, Taylor DR. The $\beta 2$-agonist controversy. Observations, explanations and relationship to asthma epidemiology. Drug Saf 1994; 11: 259-283.

33 Taylor DR, Hannah D. Management of $\beta$-agonist overuse: why and how? J Allergy Clin Immunol 2008; 122: 836-838.

34 Salpeter SR, Buckley NS, Ormiston TM, et al. Meta-analysis: effect of long-acting beta-agonists on severe asthma exacerbations and asthma-related deaths. Ann Intern Med 2006; 144: 904-912.

35 Mann M, Chowdhury B, Sullivan E, et al. Serious asthma exacerbations in asthmatics treated with high-dose formoterol. Chest 2003; 124: 70-74.

36 Chung LP, Waterer G, Thompson PJ. Pharmacogenetics of $\beta 2$ adrenergic receptor gene polymorphisms, longacting $\beta$-agonists and asthma. Clin Exp Allergy 2011; 41: 312-326.

37 Cazzola M, Calzetta L, Matera MG. $\beta_{2}$-adrenoceptor agonists: current and future direction. Br J Pharmacol 2011; 163: 4-17.

38 Peters SP, Kunselman SJ, Icitovic N, et al. Tiotropium bromide step-up therapy for adults with uncontrolled asthma. N Engl J Med 2010; 363: 1715-1726.

39 Kerstjens HA, Disse B, Schroder-Babo W, et al. Tiotropium improves lung function in patients with severe uncontrolled asthma: a randomized controlled trial. J Allergy Clin Immunol 2011; 128: 308-314.

40 Kerstjens HA, Engel M, Dahl R, et al. Tiotropium in asthma poorly controlled with standard combination therapy. N Engl J Med 2012; 367: 1198-1207.

41 Bel EH. Tiotropium for asthma - promise and caution. N Engl J Med 2012; 367: 1257-1259.

42 Chowdhury BA, Dal PG. The FDA and safe use of long-acting $\beta$-agonists in the treatment of asthma. N Engl J Med 2010; 362: 1169-1171.

43 Sears MR, Taylor DR, Print CG, et al. Regular inhaled $\beta$-agonist treatment in bronchial asthma. Lancet 1990; 336: $1391-1396$. 
Barnes PJ. Severe asthma: advances in current management and future therapy. J Allergy Clin Immunol 2012; 129: 48-59.

45 Linden A, Hansson L, Andersson A, et al. Bronchodilation by an inhaled VPAC(2) receptor agonist in patients with stable asthma. Thorax 2003; 58: 217-221.

46 Deshpande DA, Wang WC, McIlmoyle EL, et al. Bitter taste receptors on airway smooth muscle bronchodilate by localized calcium signaling and reverse obstruction. Nat Med 2010; 16: 1299-1304.

47 Zhang $\mathrm{CH}$, Chen C, Lifshitz LM, et al. Activation of BK channels may not be required for bitter tastant-induced bronchodilation. Nat Med 2012; 18: 648-650.

48 Banner KH, Press NJ. Dual PDE3/4 inhibitors as therapeutic agents for chronic obstructive pulmonary disease. Br J Pharmacol 2009; 157: 892-906.

49 Burrows B, Martinez FD, Halonen M, et al. Association of asthma with serum IgE levels and skin-test reactivity to allergens. N Engl J Med 1989; 320: 271-277.

50 Naqvi M, Choudhry S, Tsai HJ, et al. Association between IgE levels and asthma severity among African American, Mexican, and Puerto Rican patients with asthma. J Allergy Clin Immunol 2007; 120: 137-143.

51 den Otter I, Silva LF, Carvalho AL, et al. High-affinity immunoglobulin E receptor expression is increased in large and small airways in fatal asthma. Clin Exp Allergy 2010; 40: 1473-1481.

52 Wahn U, Martin C, Freeman P, et al. Relationship between pretreatment specific IgE and the response to omalizumab therapy. Allergy 2009; 64: 1780-1787.

53 Busse W, Corren J, Lanier BQ, et al. Omalizumab, anti-IgE recombinant humanized monoclonal antibody, for the treatment of severe allergic asthma. J Allergy Clin Immunol 2001; 108: 184-190.

54 Rodrigo GJ, Neffen H, Castro-Rodriguez JA. Efficacy and safety of subcutaneous omalizumab vs placebo as add-on therapy to corticosteroids for children and adults with asthma: a systematic review. Chest 2011; 139: 28-35. Strunk RC, Bloomberg GR. Omalizumab for asthma. N Engl J Med 2006; 354: 2689-2695.

56 Soler M, Matz J, Townley R, et al. The anti-IgE antibody omalizumab reduces exacerbations and steroid requirement in allergic asthmatics. Eur Respir J 2001; 18: 254-261.

57 Mascia K, Haselkorn T, Deniz YM, et al. Aspirin sensitivity and severity of asthma: evidence for irreversible airway obstruction in patients with severe or difficult-to-treat asthma. J Allergy Clin Immunol 2005; 116: 970-975.

58 ten Brinke A, Grootendorst DC, Schmidt JT, et al. Chronic sinusitis in severe asthma is related to sputum eosinophilia. J Allergy Clin Immunol 2002; 109: 621-626.

59 van Veen IH, ten Brinke A, Gauw SA, et al. Consistency of sputum eosinophilia in difficult-to-treat asthma: a 5-year follow-up study. J Allergy Clin Immunol 2009; 124: 615-617.

60 ten Brinke A, Zwinderman AH, Sterk PJ, et al. Factors associated with persistent airflow limitation in severe asthma. Am J Respir Crit Care Med 2001; 164: 744-748.

61 Bousquet J, Bachert C, Canonica GW, et al. Unmet needs in severe chronic upper airway disease (SCUAD). J Allergy Clin Immunol 2009; 124: 428-433.

62 Ragab S, Scadding GK, Lund VJ, et al. Treatment of chronic rhinosinusitis and its effects on asthma. Eur Respir J 2006; 28: 68-74.

63 Green RH, Brightling CE, McKenna S, et al. Asthma exacerbations and sputum eosinophil counts: a randomised controlled trial. Lancet 2002; 360: 1715-1721.

64 Wenzel SE, Schwartz LB, Langmack EL, et al. Evidence that severe asthma can be divided pathologically into two inflammatory subtypes with distinct physiologic and clinical characteristics. Am J Respir Crit Care Med 1999; 160: 1001-1008.

65 Bateman ED, Cheung D, Lapa e Silva, et al. Randomized comparison of ciclesonide 160 and $640 \mu \mathrm{g} /$ day in severe asthma. Pulm Pharmacol Ther 2008; 21: 489-498.

66 Hauber HP, Gotfried M, Newman K, et al. Effect of HFA-flunisolide on peripheral lung inflammation in asthma. J Allergy Clin Immunol 2003; 112: 58-63.

67 Louis R, Lau LC, Bron AO, et al. The relationship between airways inflammation and asthma severity. Am J Respir Crit Care Med 2000; 161: 9-16.

68 ten Brinke A, Zwinderman AH, Sterk PJ, et al. "Refractory" eosinophilic airway inflammation in severe asthma: effect of parenteral corticosteroids. Am J Respir Crit Care Med 2004; 170: 601-605.

69 Hashimoto S, Brinke AT, Roldaan AC, et al. Internet-based tapering of oral corticosteroids in severe asthma: a pragmatic randomised controlled trial. Thorax 2011; 66: 514-520.

70 Walsh LJ, Wong CA, Oborne J, et al. Adverse effects of oral corticosteroids in relation to dose in patients with lung disease. Thorax 2001; 56: 279-284.

71 Bernstein IL, Bernstein DI, Dubb JW, et al. A placebo-controlled multicenter study of auranofin in the treatment of patients with corticosteroid-dependent asthma. Auranofin Multicenter Drug Trial. J Allergy Clin Immunol 1996; 98: 317-324.

72 Davies H, Olson L, Gibson P. Methotrexate as a steroid sparing agent for asthma in adults. Cochrane Database Syst Rev 2000; 2: CD000391.

73 Evans DJ, Cullinan P, Geddes DM. Cyclosporin as an oral corticosteroid sparing agent in stable asthma. Cochrane Database Syst Rev 2001; 2: CD002993.

74 Nair P, Pizzichini MM, Kjarsgaard M, et al. Mepolizumab for prednisone-dependent asthma with sputum eosinophilia. N Engl J Med 2009; 360: 985-993.

75 Haldar P, Brightling CE, Hargadon B, et al. Mepolizumab and exacerbations of refractory eosinophilic asthma. N Engl J Med 2009; 360: 973-984.

76 Pavord ID, Korn S, Howarth P, et al. Mepolizumab for severe eosinophilic asthma (DREAM): a multicentre, double-blind, placebo-controlled trial. Lancet 2012; 380: 651-659.

77 Dixon AE, Pratley RE, Forgione PM, et al. Effects of obesity and bariatric surgery on airway hyperresponsiveness, asthma control, and inflammation. J Allergy Clin Immunol 2011; 128: 508-515.

78 Romagnoli I, Laveneziana P, Clini EM, et al. Role of hyperinflation vs. deflation on dyspnoea in severely to extremely obese subjects. Acta Physiol (Oxf) 2008; 193: 393-402.

79 Shore SA. Obesity, airway hyperresponsiveness, and inflammation. J Appl Physiol 2010; 108: 735-743.

80 Sabate JM, Jouet P, Merrouche M, et al. Gastroesophageal reflux in patients with morbid obesity: a role of obstructive sleep apnea syndrome? Obes Surg 2008; 18: 1479-1484. 
81 Mosen DM, Schatz M, Magid DJ, et al. The relationship between obesity and asthma severity and control in adults. J Allergy Clin Immunol 2008; 122: 507-511.

82 Stenius-Aarniala B, Poussa T, Kvarnstrom J, et al. Immediate and long term effects of weight reduction in obese people with asthma: randomised controlled study. BMJ 2000; 320: 827-832.

83 Julien JY, Martin JG, Ernst P, et al. Prevalence of obstructive sleep apnea-hypopnea in severe versus moderate asthma. J Allergy Clin Immunol 2009; 124: 371-376.

84 Luyster FS, Teodorescu M, Bleecker E, et al. Sleep quality and asthma control and quality of life in non-severe and severe asthma. Sleep Breath 2012; 16: 1129-1137.

85 Alkhalil M, Schulman ES, Getsy J. Obstructive sleep apnea syndrome and asthma: the role of continuous positive airway pressure treatment. Ann Allergy Asthma Immunol 2008; 101: 350-357.

86 Lafond C, Series F, Lemiere C. Impact of CPAP on asthmatic patients with obstructive sleep apnoea. Eur Respir J 2007; 29: 307-311.

87 Mastronarde JG, Anthonisen NR, Castro M, et al. Efficacy of esomeprazole for treatment of poorly controlled asthma. N Engl J Med 2009; 360: 1487-1499.

88 Castro M, Mathur S, Hargreave F, et al. Reslizumab for poorly controlled, eosinophilic asthma: a randomized, placebo-controlled study. Am J Respir Crit Care Med 2011; 184: 1125-1132.

89 Wenzel SE, Barnes PJ, Bleecker ER, et al. A randomized, double-blind, placebo-controlled study of tumor necrosis factor-alpha blockade in severe persistent asthma. Am J Respir Crit Care Med 2009; 179: 549-558.

90 Berry MA, Hargadon B, Shelley M, et al. Evidence of a role of tumor necrosis factor alpha in refractory asthma. N Engl J Med 2006; 354: 697-708.

91 Morjaria JB, Chauhan AJ, Babu KS, et al. The role of a soluble TNF $\alpha$ receptor fusion protein (etanercept) in corticosteroid refractory asthma: a double blind, randomised, placebo controlled trial. Thorax 2008; 63: 584-591.

92 Busse WW, Israel E, Nelson HS, et al. Daclizumab improves asthma control in patients with moderate to severe persistent asthma: a randomized, controlled trial. Am J Respir Crit Care Med 2008; 178: 1002-1008.

93 Nair P, Gaga M, Zervas E, et al. Safety and efficacy of a CXCR2 antagonist in patients with severe asthma and sputum neutrophils: a randomized, placebo-controlled clinical trial. Clin Exp Allergy 2012; 42: 1097-1103.

94 Corren J, Lemanske RF, Hanania NA, et al. Lebrikizumab treatment in adults with asthma. N Engl J Med 2011; 365: 1088-1098.

95 Piper E, Brightling C, Niven R, et al. A phase II placebo-controlled study of tralokinumab in moderate-to-severe asthma. Eur Respir J 2013; 41: 330-338.

96 Corren J, Busse W, Meltzer EO, et al. A randomized, controlled, phase 2 study of AMG 317, an IL-4R $\alpha$ antagonist, in patients with asthma. Am J Respir Crit Care Med 2010; 181: 788-796.

97 Cox PG, Miller J, Mitzner W, et al. Radiofrequency ablation of airway smooth muscle for sustained treatment of asthma: preliminary investigations. Eur Respir J 2004; 24: 659-663.

98 Cox G, Miller JD, McWilliams A, et al. Bronchial thermoplasty for asthma. Am J Respir Crit Care Med 2006; 173: 965-969.

99 Cox G, Thomson NC, Rubin AS, et al. Asthma control during the year after bronchial thermoplasty. N Engl J Med 2007; 356: 1327-1337.

100 Castro M, Rubin AS, Laviolette M, et al. Effectiveness and safety of bronchial thermoplasty in the treatment of severe asthma: a multicenter, randomized, double-blind, sham-controlled clinical trial. Am J Respir Crit Care Med 2010; 181: 116-124.

101 Thomson NC, Rubin AS, Niven RM, et al. Long-term (5 year) safety of bronchial thermoplasty: Asthma Intervention Research (AIR) trial. BMC Pulm Med 2011; 11: 8.

102 Rijssenbeek-Nouwens LH, Bel EH. High-altitude treatment: a therapeutic option for patients with severe, refractory asthma? Clin Exp Allergy 2011; 41: 775-782.

103 Karagiannidis C, Hense G, Rueckert B, et al. High-altitude climate therapy reduces local airway inflammation and modulates lymphocyte activation. Scand J Immunol 2006; 63: 304-310.

104 Wheelock CE, Goss VM, Balgoma D, et al. Application of 'omics technologies to biomarker discovery in inflammatory lung diseases. Eur Respir J 2013 [Epub ahead of print DOI: 10.1183/09031936.00078812]. 